\title{
Spusubsaúde
}

\section{A comunicação como estratégia de cuidado com pacientes hospitalizados}

\author{
The Communication as a care strategy for hospitalized patients
}

\author{
Jaquilene Barreto da $\operatorname{Costa}^{1^{*} \bullet}$,Gabriel Afonso Dutra Kreling ${ }^{2} \bullet$
}

\begin{abstract}
${ }^{1}$ Hospital Universitário do Oeste do Paraná, Departamento de Psicologia, Cascavel, Paraná, Brasil. ${ }^{2}$ Médico. Equipe de Cuidados Paliativos do Hospital Universitário do Oeste do Paraná - Universidade Estadual do Oeste do Paraná - Cascavel, Paraná, Brasil *Autor para correspondência. E-mail: jaquihuop@yahoo.com.br
\end{abstract}

\section{Ponto de Vista}

Palavras-chave: comunicação em saúde, hospitalização, equipe de assistência ao paciente, angústia psicológica.

Keywords: health communication, hospitalization, patient care team, psychological distress.

\section{Introdução}

Há uma variedade de modelos e definições de comunicação, isto significa que comunicar é um ato complexo que requer habilidade e treinamento. Comunicar é tornar comum, é pôr em comunicação, significa: partilhar, trocar, fazer saber. É basicamente a interação verbal e não verbal entre dois ou mais indivíduos, em diferentes contextos e sob perspectivas próprias. Assim, o ato de comunicar é dinâmico, envolve sentimento, interação, interpretação, compreensão e adaptação, tanto para aquele que comunica, quanto para quem recebe.

Desse modo, uma boa comunicação não supõe apenas informar ao paciente sobre sua enfermidade, tratamento e evolução, mas sobretudo, se dá a partir de uma relação de ajuda, compreendendo as reações emocionais frente ao adoecimento e suas implicações nas diferentes esferas de sua vida - família, trabalho, amigos, crenças, espiritualidade. Portanto, a qualidade dos relacionamentos entre a tríade equipe/paciente/família e a relação de confiança construída a partir de uma comunicação eficiente são aspectos fundamentais para minimizar o sofrimento emocional de todos os envolvidos, garantir a dignidade e qualificar a vida neste momento.

\section{Mesmo diante de uma má notícia uma boa comunicação pode ser terapêutica}

Uma má notícia não significa apenas um conteúdo difícil a ser transmitido, significa uma quebra de expectativa, uma ruptura do seu mundo presumido e na perspectiva de futuro. Dependendo do contexto, uma notícia ruim tende a levar à experiência de sofrimento, mas a forma de comunicação pode proporcionar ferramentas adaptativas e de ressignificação capazes de transformar o sofrimento. Pode-se dizer, pois, que o conteúdo da comunicação pode ser de uma notícia difícil, mas que a consequência deste conteúdo em quem o recebe produzirá respostas emocionais intensas a depender de como será transmitido.

A habilidade de comunicação poderá ser um elemento terapêutico em si quando facilita a expressão de mecanismos adequados para fazer frente ao sofrimento e favorece uma atenção integral ao paciente contemplando os aspectos físicos, psicológicos, sociais e espirituais. A relação-comunicação adquire seu máximo valor terapêutico quando, a partir dela, o profissional exerce um papel de continente das ansiedades, medos e sentimentos tanto do paciente quanto dos familiares (Benítez del Rosario \& Asensio Fraile, 2002).

Portanto, para que a comunicação seja uma ferramenta terapêutica deverá ser estruturada de acordo com algumas características importantes: uma comunicação que contemple aspectos positivos sobre a situação, como opções de tratamento e controle de sintomas; que esteja alinhada com o conhecimento e 
informações que o paciente e familiares têm sobre a doença, que leve em consideração as ideias e crenças e que a autonomia e a dignidade do paciente sejam mantidas durante todo o acompanhamento. $\mathrm{O}$ estabelecimento de uma relação de ajuda baseada no comprometimento, na empatia, na demonstração de confiança, na veracidade das palavras utilizadas, na privacidade e na confidencialidade, são fatores também importantes (Muller, 2002).

Quadro 1. Comunicando com cuidado.

\begin{tabular}{|c|c|}
\hline Objetivos do comunicar terapêutico & Ruídos que interferem na comunicação \\
\hline Oferecer um espaço de escuta e acolhimento. & Espaço físico inadequado, sem privacidade \\
\hline $\begin{array}{l}\text { Oferecer uma informação baseada no que o paciente já sabe, a } \\
\text { informação deverá ser progressiva e “titulada” de acordo com a } \\
\text { tolerabilidade do paciente/família. }\end{array}$ & $\begin{array}{l}\text { Falar em demasia, ser repetitivo, não ter disponibilidade para } \\
\text { ouvir }\end{array}$ \\
\hline $\begin{array}{l}\text { Oferecer uma informação adaptada ao estado emocional do } \\
\text { paciente. }\end{array}$ & Uso de jargões e termos técnicos \\
\hline Facilitar a expressão de sentimentos, validar as emoções. & $\begin{array}{l}\text { Dificuldade do profissional em reconhecer e respeitar a } \\
\text { autonomia do paciente }\end{array}$ \\
\hline $\begin{array}{l}\begin{array}{l}\text { Reduzir o sofrimento psicológico do paciente/família, seja } \\
\text { empático. }\end{array}\end{array}$ & $\begin{array}{l}\text { Não reconhecer as diferenças e posições de cada membro da } \\
\text { família }\end{array}$ \\
\hline Aumentar a adesão ao tratamento, seja consistente e verdadeiro. & $\begin{array}{l}\text { Desconhecer a história clínica, evolução e prognóstico do } \\
\text { paciente }\end{array}$ \\
\hline $\begin{array}{l}\text { Facilitar a tomada de decisões compartilhadas, forneça } \\
\text { informações claras, importantes e objetivas. }\end{array}$ & $\begin{array}{l}\text { Falta de preparo e ansiedade do profissional diante da } \\
\text { comunicação de uma notícia difícil }\end{array}$ \\
\hline $\begin{array}{l}\text { Fortalecer a relação e a confiança entre equipe/paciente/família, } \\
\text { ouça sem julgamentos. }\end{array}$ & $\begin{array}{l}\text { Medo do profissional das possíveis consequências negativas da } \\
\text { informação a ser dada }\end{array}$ \\
\hline
\end{tabular}

\section{Comunicação de más notícias}

Comunicar uma má notícia pode ser um grande desafio e a forma de se transmitir a informação pode trazer muita angústia ao paciente e família. Portanto, tem mais impacto o "como" se informa e não o "que" se informa, sendo estes os dois elementos indispensáveis da comunicação (Fujimori \& Uchitomi, 2009). Assim, uma boa comunicação afeta positivamente o bem-estar do paciente, sua adequação psicológica à situação e fortalece o vínculo com a equipe.

Reações emocionais são comuns tanto para a equipe quanto para o paciente e família em momentos de comunicação de uma notícia difícil e, por vezes, o manejo das emoções não é tido como importante. Validar as emoções é uma intervenção necessária que traz alívio, significa apoio, demonstração de interesse e cuidado com o paciente e família.

Quadro 2. Boas práticas para uma comunicação terapêutica.

Lembre-se que a maioria dos pacientes e familiares desejam informações claras e honestas

Analise em que momento da vida do paciente a doença se instalou - o quanto ele abriu mão de seus planos, projetos de vida.

Ouça, procure compreender o que o paciente já sabe sobre sua condição e quais termos se utiliza para explicar essa realidade.

Identifique as necessidades específicas de informações e preferências do paciente/familiar - o que, e o quanto paciente/família desejam saber.

Identifique a disponibilidade para tomada de decisão de pacientes e familiares - grau de envolvimento e o quanto desejam participar na tomada de decisões.

Evite que as informações indesejadas sejam oferecidas precocemente - observe o quanto o paciente/família, estão prontos para ouvir.

Identifique o status emocional do paciente/família e dificuldades enfrentadas para facilitar que informações e decisões sejam tituladas de acordo com as necessidades especificas.

Leve em consideração os valores dos envolvidos e expressões de desejos prévios.

Ajude o paciente e familiares a tomarem decisões consistentes com os objetivos dos cuidados. 


\section{Fundamentos da comunicação terapêutica}

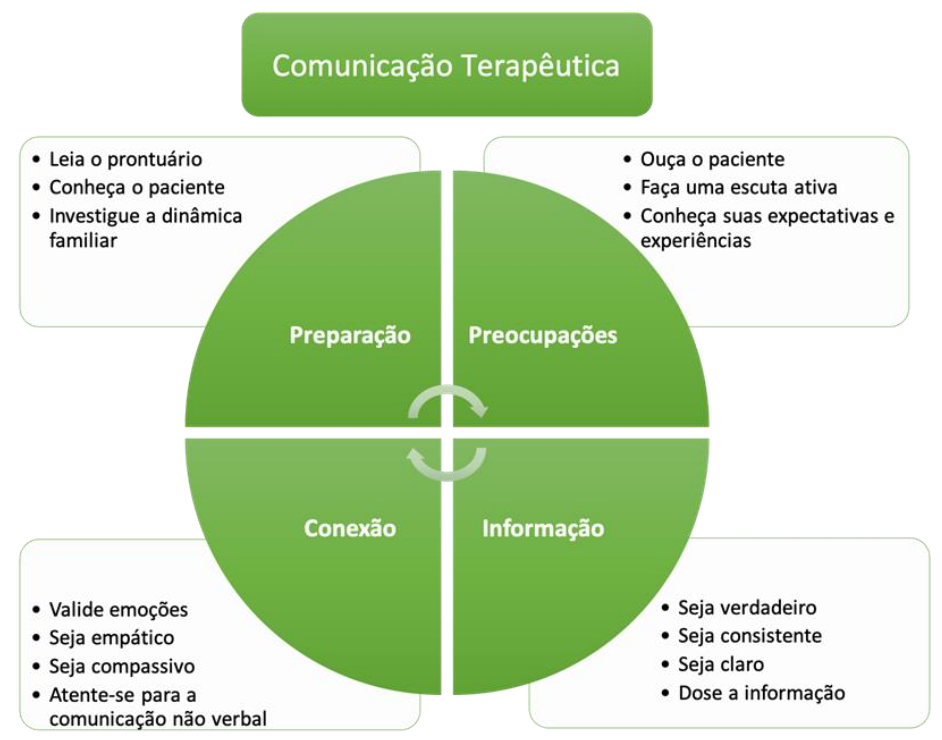

Figura 1. Fundamentos para uma comunicação terapêutica. Elaborado pelos autores.

\section{Modos de sentir}

A doença se impõe ao paciente desencadeando reações diversas. O humor pode oscilar entre extremos: da tristeza ao desamparo, da revolta ao desespero; outros podem sentir-se anestesiados e, contrastando com essa vivência, alguns podem exibir uma aparente tranquilidade e aceitação.

A presença de reações dessa natureza contraindica a comunicação nesse momento, principalmente quando se trata de uma doença que ameaça à vida, situação que provoca alto grau de ansiedade e de ameaça à sua integridade. Atentar-se para as reações emocionais que são mobilizadas para lidar com situações angustiantes ajuda o profissional a decidir qual o melhor momento para fazer a comunicação. Além disso, as reações emocionais podem servir como indicador para que a equipe realize uma comunicação de forma dosada, suportável e progressiva de acordo com as condições emocionais do paciente e familiares.

Portanto, não existe fórmula exata para comunicar notícias difíceis que sirvam igualmente a todos no que diz respeito ao volume de informações e ao momento correto para prestá-las. Fornecer informações detalhadas para quem não deseja ou ainda não está preparado para recebê-las pode fragilizar ainda mais o paciente. Por outro lado, informações insuficientes podem levar a sentimentos de alienação por parte de outros, gerando frustrações, desconfianças e conflitos com a equipe (Moritz, 2020).

\section{Duas ferramentas indispensáveis na comunicação}

Ouvir é uma ferramenta indispensável para uma boa comunicação. Não há outra forma de se inteirar de quais temores e sentimentos afligem o paciente, bem como do significado e das implicações que o adoecimento traz, a não ser ouvindo-o com disponibilidade de tempo, com respeito às ideias, dúvidas e sentimentos a nós expressados (Botega, 2017). Assim, o saber ouvir com atenção, muito mais do que falar, vai nos indicar o que realmente o paciente necessita, do que quer ou não saber. Quando o paciente quer uma explicação, esclarecimentos sobre sua doença ele sinaliza que tem condições de receber a informação e previamente já avaliou as possibilidades de respostas. Contudo, todo paciente tem o direito de saber sobre sua doença, mas nem todo paciente tem o desejo de saber.

Já o silêncio é reconhecido como parte integrante da comunicação interpessoal e do cuidado compassivo. Falar através de um olhar, de um toque afetivo, ou do silêncio que faz conexão com os sentimentos despertados após uma notícia ruim, pode ser por vezes necessário, além de ser reconfortante. O silêncio deve ser usado como uma ferramenta que permite ao profissional expressar sua compaixão, compreensão e, sobretudo, para legitimar a dor do paciente e família.

A nossa tendência como profissionais dispostos a ajudar e sermos resolutivos é frequentemente traduzida por uma necessidade intrínseca de agir, responder absolutamente tudo com palavras, fornecer respostas, dizer alguma coisa, como se tudo pudesse ou devesse ser respondido. De certa forma temos baixa tolerância ao silêncio do outro e ao próprio silêncio. Isso nos causa angústia e desconforto (Sapeta \& Simões, 2018). 
Há momentos que a dor e o sofrimento pedem silêncio e reflexão. Não há mais necessidade de explicações e informações, as palavras fazem pouco sentido e dão lugar a compreensão da dura realidade. É hora de fazer silêncio para que as emoções e sentimentos emerjam e sejam percebidas, sentidas, compreendidas e acolhidas por todos que estão a compartilhar desse momento - paciente, família e equipe. Desse modo, o silêncio deve ser utilizado como uma estratégia de cuidado. Sons profundos e benéficos, carregados de sentimentos, só são perceptíveis quando estamos em silêncio. O silêncio aqui tratado não significa ausência de fala, significa uma presença ativa e consciente do contexto na escuta dos sons que permeiam esse momento (Bassett et al., 2018).

Quando as palavras não dão mais conta do momento é a hora de trocá-las por um toque afetivo, um olhar compreensivo, um ouvir mais profundo, um estar presente, compartilhando o silêncio e a dor. O respeito pelo silêncio do paciente implica um profundo respeito a sua pessoa, ao momento vivido, além disso é um ato sublime que demonstra a ética do profissional de saúde (Sapeta \& Simões, 2018).

Precisamos aprender a cuidar em silêncio, especialmente nos momentos de extrema dor emocional, mas para isso, precisamos saber falar e ouvir através do silêncio. Dos sons que vem do silêncio podemos ouvir e entrar em contato com sentimentos e emoções profundas: angústia, tristeza, medo, solidão, mas também podemos ouvir um profundo diálogo com a vida, que ressignifica o sofrimento e traz paz interior.

\section{Reconhecendo os tipos de silêncio}

Por ser uma ferramenta fundamental no cuidado, o silêncio não deve ser usado como escudo para lidar com a nossa impotência, para nos proteger de situações embaraçosas e da falta de habilidade para lidar com momentos difíceis. Ficar em silêncio na presença do outro que sofre é um ato desafiador e, às vezes, pode ser gerador de extremo desconforto.

Há vários tipos de silêncios. Silêncios frios, que julgam, que ignoram, esses são por vezes, usados como escudos para aplacar as dificuldades em lidar com situações difíceis ou usados como estratégia para lidar com o sofrimento. Há os silêncios quando alguém atravessa o fim da vida, esses, precisam de atenção, pois podem não ser benéficos ao paciente, às vezes, são carregados de angústia, medo e muito sofrimento, e quando usados como fuga, precisam ser quebrados. Há o silêncio que nega a realidade "conspiração \pacto do silêncio" que ignora o desejo e a autonomia do paciente, esse não ajuda, quebra vínculos. Há o silêncio de quem cuida, aquele que após a morte de um paciente, não ousamos em nos expressar e retornamos para agitação diária para não ouvir o pulsar de nossos sentimentos, esse silêncio se torna pesado demais para suportar.

Mas há o silêncio que aproxima, que conecta, o silêncio como presença ativa, que te coloca no lugar daquele que falou no momento certo e se calou quando não havia mais a ser dito, é quando o silêncio se torna a única forma de comunicação. Agora o diálogo é com a vida, com o que importa, com a presença.

Assim, os silêncios criam um espaço de escuta e aprofundam a nossa compreensão do outro e de nós mesmos. Há silêncios que angustiam, que separa, que ignora, mas há também aqueles que reconfortam, e são carregados de compaixão. Então, para reconhecer a voz do silêncio talvez possamos focar nossa atenção no paciente, no ambiente e em si mesmo, para que possamos ouvir ativamente e refletir qual silêncio está presente para então respeitá-lo, compartilhar e aprender com ele.

\section{Considerações finais}

Preparação, preocupação, informação e conexão são fundamentos da comunicação terapêutica que devem ser atentamente respeitados. Comunicar não significa, necessariamente, falar. Ouvir e silenciar são também etapas e ferramentas de comunicação que propiciam a assertividade e o respeito ao momento experienciado pelo paciente e família.

A comunicação é uma das ferramentas basilares do cuidado. É, pois, imperativo o treinamento e o refinamento desta habilidade, A comunicação terapêutica permite a ressignificação e a conexão, sendo, portanto, divisora de desfechos.

\section{Referências}

Bassett, L., Bingley, A. F., \& Brearley, S. G. 2018. Silence as an element of care: A meta-ethnographic review of professional caregivers experience in clinical and pastoral settings. Palliative Medicine, 32(1), 185-194.

Benítez del Rosario, M. A., \& Asensio Fraile, A. 2002. La comunicacion com el paciente com enfermedad em fase terminal. Atención Primaria, 30(7), 463-466. 
Botega, N. J. 2017. Prática psiquiátrica no hospital geral: interconsulta e emergência. $4^{\mathrm{a}}$ ed. Porto Alegre: Artemed, 536p.

Fujimori, M., \& Uchitomi, Y. 2009. Preferences of cancer patients regarding communication of bad news: a systematic literature review. Japanese Journal of Clinical Oncology, 39(4), 201-216.

Moritz, R. D. 2020. Cuidados de fim de vida em UTI. In: Moritz, R. D., Kretzer, L. P., \& Rosa, R. G. Cuidados Paliativos, Comunicação e Humanização em UTI. $1^{\text {a }}$ ed. Rio de janeiro: Atheneu, 328p.

Muller, P. Breaking Bad news to patients - The SPIKES approach can make this difficult task easier. Postgraduate Medicine, 2002; 112(3):1-6.

Sapeta, P., \& Simões, A. 2018. Silences in palliative care-the primacy of human presence. Hospice \& Palliative Medicine International Journal, 2(3), 161-164.

\section{Minicurrículo}

Jaquilene Barreto da Costa. Psicóloga pela Universidade Federal da Paraíba-PR em 1998. Mestre em Ciências da Saúde pela Universidade Estadual de Maringá-PR. Psicóloga concursada pela Unioeste - Universidade Estadual do Oeste do Paraná, atuando há 20 anos no Departamento de Psicologia do Hospital Universitário do Oeste do Paraná. Coordenadora do projeto de pesquisa e extensão do ambulatório de seguimento em Terapia Intensiva do HU, membro da comissão de cuidados paliativos adulto e pediátrico.

Gabriel Afonso Dutra Kreling. Médico pela Universidade Estadual de Londrina. Especialista em Clínica Médica pela Universidade de São Paulo. Pós-graduado em Cuidados Paliativos pela Universidad del Salvador, Buenos Aires - Argentina.

Como citar: Costa, J.B., \& Kreling, G.A.D. 2021. A comunicação como estratégia de cuidado com pacientes hospitalizados. Pubsaúde, 6, a211. DOI: https://dx.doi.org/10.31533/pubsaude6.a211

Recebido: 9 jun. 2021.

Revisado e aceito: 24 jun. 2021.

Conflito de interesse: os autores declaram, em relação aos produtos e companhias descritos nesse artigo, não ter interesses associativos, comerciais, de propriedade ou financeiros que representem conflito de interesse.

Licenciamento: Este artigo é publicado na modalidade Acesso Aberto sob a licença Creative Commons Atribuição 4.0 (CC-BY 4.0). 